\title{
T lymphocytes in IgA nephropathy (Review)
}

\author{
YUYAN TANG, HAIDONG HE, PIN HU and XUDONG XU \\ Department of Nephrology, Minhang Hospital, Fudan University, Shanghai 201199, P.R. China
}

Received September 19, 2019; Accepted March 19, 2020

DOI: $10.3892 /$ etm.2020.8673

\begin{abstract}
Immunoglobulin A nephropathy (IgAN), the most common primary glomerulonephritis worldwide, is the main cause of end-stage renal disease. IgAN is characterized by the accumulation of immune complexes in the circulation, which contain abnormal levels of $\operatorname{IgA}$. IgAN primarily results from galactose-deficient IgA1 (Gd-IgA1) and Gd-IgA1 deposition in the renal mesangium, causing local proliferation and matrix expansion. Gd-IgA1 has been confirmed as one of the key effectors in the pathogenesis of $\operatorname{Ig} \mathrm{AN}$, but the origin of Gd-IgA1 is not clear. Recent studies have shown that Gd-IgA1 deposition could be the result of mucosally primed plasma cells and is associated with $\mathrm{T}$ cell dysregulation. $\mathrm{T}$ cells contribute to the IgA response and play an important role in the development of IgAN. In the present review, the latest discoveries regarding the role of $\mathrm{T}$ lymphocytes in the pathogenesis of $\operatorname{IgAN}$ have been summarized. Understanding these advances will allow novel therapeutic strategies for the treatment of $\operatorname{IgAN}$.
\end{abstract}

\section{Contents}

1. Introduction

2. T lymphocyte classification

3. Role of T lymphocytes in IgAN

4. Th1/Th2 lymphocytes

5. Th17 lymphocytes

6. TFH cells

7. Tregs

8. Th22 cells

9. $\mathrm{CD}^{+}$cells

10. Imbalance of $\mathrm{T}$ cell subsets as a target for the treatment of IgAN

11. Future perspectives

12. Conclusions

Correspondence to: Dr Xudong Xu or Dr Yuyan Tang, Department of Nephrology, Minhang Hospital, Fudan University, 170 Xinsong Road, Shanghai 201199, P.R. China

E-mail: xxdmzx@sina.com

E-mail: tangyuyan361113248@163.com

Key words: IgA nephropathy, pathogenesis, galactose-deficient IgA1, T lymphocyte, B lymphocyte

\section{Introduction}

Immunoglobulin A nephropathy (IgAN) is the most common primary glomerulonephritis in the world, which normally leads to end-stage renal disease. It is characterized by the overexpression of IgA1 molecules, with low galactosylation in the serum and mesangium of the kidney $(1,2)$. There are two subclasses of $\operatorname{Ig} \mathrm{A}$ in humans, $\operatorname{Ig} \mathrm{A} 1$ and $\operatorname{IgA} 2$. The main difference between $\operatorname{IgA} 1$ and $\operatorname{Ig} \mathrm{A} 2$ is that there is a hinge region (HR) in the IgA1 heavy chain (3). Furthermore, in the HR of the heavy chain, there are 3 to $6 O$-glycans connected to either a serine or threonine; the HR is co-translated/post-translated by the addition of up to $6 O$-glycan chains (4). These chains include $N$-acetylgalactosamine (GalNAc), which is linked by $\mathrm{O}$-linkage with serine or threonine residues. The galactose within GalNAc may be $\beta-1,-3$ using the enzyme core $1 \beta$-1,3-galactosyltransferase (C1GalT1; the key enzyme of galactosylation), which requires assistance from the molecular chaperone, Cosmc; and is essential for correct folding and stability. Galactose residues and GalNAc can be sialylated in a 2, 3- or a 2, 6-configuration, respectively.

Although the exact pathogenesis of IgAN remains unclear, it is hypothesized to be associated with the immune imbalance in the human body. Furthermore, the decreased expression level of the molecular chaperone Cosmc in B cells of patients with $\operatorname{IgAN}$ is associated with the number of B cells and the abnormal glycosylation of $\operatorname{IgA1}$ in $\operatorname{IgAN}(5-8)$. However, the production of IgA1 with low galactosylation in $\operatorname{IgAN}$ may be the result of B cell defect, and the activity of C1GalT1 is decreased in B cells (9). This is consistent with the observation that an increasing number of poly IgA1 (pIgA1) plasma cells are found in the bone marrow and tonsils of patients with IgAN with the inactivation of C1GalT1 of B cells, and the increase in IgA1 synthesis of these plasma cells in spontaneous culture is also observed $(10,11)$. Notably, pIgA1 is produced by polyclonal active B cells, and the process of IgA production by B cells is regulated by $\mathrm{T}$ cells. Lymphocytes induced by mucosal antigens produce abnormal amounts of poorly glycosylated $\operatorname{Ig} \mathrm{A} 1$ and polymerized $\mathrm{IgA}-\mathrm{IgG}$ immune complexes $(12,13)$. $\mathrm{T}$ lymphocytes play a key role in the control of antigen-driven adaptive immune response; in particular the polarization of T helper (Th) cells can affect IgAN (14-16).

It remains unclear where galactose-deficient IgA1 (Gd-IgA1) originates; however, an increasing number of studies have revealed that Gd-IgA1 deposition could be derived from mucosally primed plasma cells, which is related to the imbalance of a subset of T cells (17). Furthermore, previous studies 
have revealed that impaired mucosal IgA response may lead to impaired mucosal antigen clearance. Mucosal immunity depends on a delicate balance between antigen reactivity and tolerance. $\mathrm{CD}^{+} \mathrm{T}$ cell subsets play a vital role in maintaining or destroying this balance (18). Recent studies suggest that Th2 type cytokines are the main cytokines secreted by circulating $\mathrm{T}$ cells in IgAN. Th2 type cytokines could trigger over-secretion of abnormal glycosylation of $\operatorname{IgA} 1$, which is easy to deposit in the mesangium (19). However, additional reports also revealed that the strong polarization of $\mathrm{Th} 1$ in $\operatorname{Ig} \mathrm{AN}$, and the advantage of Th1 is associated with the development of renal injury in IgAN (20-23). In a recent study, the upregulation of $\mathrm{CX} 3 \mathrm{CR} 1^{+} \mathrm{CD}^{+} \mathrm{T}$ cells in the tonsils was found in patients with $\operatorname{Ig} \mathrm{AN}$ (24). Taken together, these findings revealed that $\mathrm{T}$ lymphocytes play an important role in the development of IgAN. T cell dysregulation may induce B cells to secrete excessive and abnormal levels of IgA1, which can lead to IgA deposition in the glomerular and lead to injury.

In the present review, the roles of T lymphocytes in IgAN are highlighted from the literature. Furthermore, the role of $\mathrm{T}$ lymphocytes in the pathogenesis of $\mathrm{Ig} \mathrm{AN}$ and their potential as therapeutic interventions and biomarkers for the treatment and monitoring of IgAN will also be discussed.

\section{T lymphocyte classification}

$\mathrm{CD}^{+} \mathrm{T}$ cells, including Treg and effector Th cells, play a key role in the host defense. However, the imbalance of $\mathrm{CD}^{+} \mathrm{T}$ cell differentiation leads to chronic infections as well as a variety of inflammatory allergic and autoimmune diseases, such as chronic hepatitis B virus infection (25), rhinallergosis (26) and IgAN (27). The differentiation and functions of $\mathrm{CD}^{+} \mathrm{T}$ cell subsets are dependent upon the cytokine environment, which enables the differentiation into several distinct subtypes to coordinate the immune response to clear the pathogenic insult. At present, with respect to the lineage-specific transcription factors, several different $\mathrm{T}$ cell subtypes have been identified: T-bet for Th1 cells, GATA3 for Th2 cells, ROR $\gamma$ t for Th17, the master regulator Foxp3 for Treg cells, and Bcl6 for follicular helper T cells (TFH cells) $(28,29)$. Each of these $\mathrm{T}$ cell subtypes have specific characteristic cytokines and performs various immune functions according to the type of cytokines (30). Th1 cells produce pro-inflammatory cytokines, including interleukin (IL)-2 and interferon (IFN)- $\gamma$, which contribute to cellular immunity and clearance of intracellular pathogens. Meanwhile, Th2 cells secrete anti-inflammatory cytokines, including IL-4 and IL-10, which are essential for humoral-mediated immunity of extracellular pathogens (31-33). In addition, Th17 cells include another subset of Th cells characterized by the secretion of IL-17 (34). The Th17 lineage has been revealed to play an important role in the early response to bacterial pathogens and the initiation of autoimmune diseases, such as rheumatoid arthritis, IgAN and allergen-specific responses (35). Furthermore, $\mathrm{CD} 4^{+} \mathrm{CD} 25^{+}$Treg cells are a subgroup of inhibitory $\mathrm{T}$ cells, including natural Treg (nTregs), inducible Treg (iTregs) and thymus-derived Treg (tTregs) cells, and play a crucial negative regulatory role in the immune system $(36,37)$. In a recent study, TFH cells have been revealed to be important subsets of $\mathrm{T}$ cells involved in the regulation of $\mathrm{B}$ cell activation and the formation of the germinal center, which can enhance the humoral response (38). Similarly, $\mathrm{CD}^{+} \mathrm{T}$ cells are part of the adaptive immune response. With the help of $\mathrm{CD}^{+} \mathrm{T}$ cells, they can effectively eliminate viruses $(39,40)$. Novel T-lymphocyte subsets are expected to be identified in the future.

\section{Role of T lymphocytes in IgAN}

T cells are important cells, which control antigen-driven adaptive immune response. Inappropriate differentiation of T cells leads to chronic infection, as well as to various autoimmune diseases, such as glomerulonephritis (41). Thus, it is important to identify and understand the mechanisms underlying the preferential induction of each of these T cell subsets. IgAN is hypothesized to be associated with the immune abnormality of $\mathrm{T}$ cells, which leads to abnormal signal transduction and changes in B cell response $(17,42)$ (Fig. 1). For example, in an animal model of IgAN, ddy mice showed strong polarization to Th1 in the early stage of the disease (43). In addition, the expression of T-bet in urine sediment of newly diagnosed children with IgAN was found to be higher compared with that in the control group, which is associated with the positive staining of T-bet protein in renal biopsy tissue (44). Meanwhile, Th2 cytokine IL-4 may play an important role in controlling the glycosylation of the IgA1 HR (45) and renal fibrosis (46). Furthermore, the Th1:Th2 ratio is associated with proteinuria and renal pathologic changes in the $\operatorname{IgAN}$ group (47). As specific specialized signature cytokines, and the imbalance of $\mathrm{T}$ cells in blood samples are relatively stable and easy to quantify, there is potential for these to be used as biomarkers for the treatment and monitoring of diseases. However, there is limited research on the role of $\mathrm{T}$ cell subsets in the pathogenesis of IgAN and their potential application as new therapeutic targets. Therefore, further research is urgently needed to address this shortfall. Here, the current literature on $\mathrm{T}$ cell subsets associated with $\mathrm{IgAN}$ is reviewed.

\section{Th1/Th2 lymphocytes}

It is widely known that $\operatorname{IgAN}$ is the most common immune complex associated with the cause of glomerulonephritis in the world $(48,49)$. There is emerging evidence which shows that the imbalance of Th1/Th2 pro-inflammatory cytokines plays an important role in the development and progression of $\operatorname{IgAN}(42,43)$. Th1 cells induce cytotoxic and cell-mediated immunity by the secretion of IL-2, IFN- $\gamma$ and tumor necrosis factor (TNF)- $\alpha$, and antagonize Th 2 cell function. By contrast, Th2 cells adjust humoral immunity via the predominant secretion of IL-4, IL-5, IL-6, and IL-13, and antagonize Th1 cell function (18). On the one hand, it was reported that in an animal model of $\operatorname{IgAN}$, ddy mice showed strong polarization to Th1 in the early stage of the disease (43), while those with quiescent disease were Th2 polarized. The level of $\operatorname{IgA} / \operatorname{IgG} 2 \mathrm{a}$ immune complex in the serum was found to be significantly associated with the degree of glomerular lesions (20). In another study, bioinformatic analysis further revealed that three regions were aberrantly methylated and affected the genes of $\mathrm{CD}^{+}$ $\mathrm{T}$ cell response and proliferation in patients with IgAN. This included a total of two hypomethylated regions arranged in genes, including TCR (T-cell receptor) signaling, DUSP3 


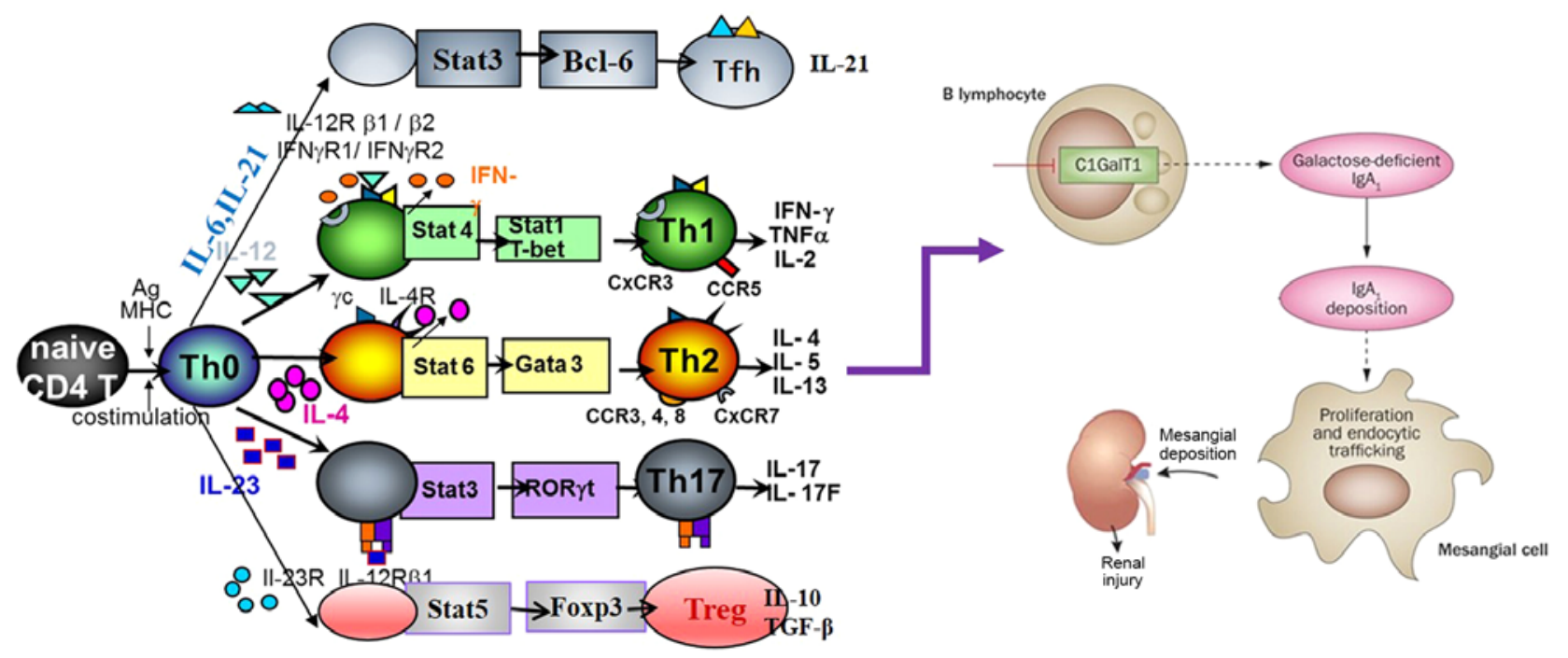

Figure 1. T cells in the pathogenesis of $\operatorname{Ig}$ A nephropathy. $\operatorname{IgA}$ nephropathy (IgAN) is characterized by the accumulation of immune complexes in the circulation. It is mainly composed of galactose-deficient IgA1 (Gd-IgA 1) and Gd-IgA1 deposition in the renal mesangium, causing local proliferation and matrix expansion. Gd-IgA1 has been confirmed as one of the key effectors in the pathogenesis of IgAN. Recent studies have shown that T lymphocytes play a crucial role in the development of IgAN. T-cell dysregulation may induce B cells to secrete excessive and abnormal IgA1, leading to IgA deposition in the glomerulus and injury. Stat, signal transducer and activator of transcription; IL, interleukin; Tfh, follicular helper T cell; Th, helper T cell; IFN, interferon; TNF $\alpha$, tumor necrosis factor $\alpha$; TGF- $\beta$, transforming growth factor $\beta$.

(dual-specificity phosphatase 3) and TRIM27 (tripartite motif-containing 27), and a hypermethylated region involved in VTRNA2-1 (vault RNA 2-1) non-coding RNA, also considered as the microRNA (miR)-886 precursor. Moreover, the hypermethylation of the miR-886 precursor led to the decrease in $\mathrm{CD}^{+}{ }^{+} \mathrm{T}$ cell proliferation and the overexpression of TGF- $\beta$ after TCR stimulation, which has been proven to induce the transformation of $\operatorname{IgA}$ and $\operatorname{IgG} 2$, and increase the secretion of $\operatorname{IgA} 1$ and $\operatorname{IgA} 2$ in human B cells (50-52). In a study by Sallustio et al (50), the ratio of IL-2/IL-5 was significantly increased in patients with $\operatorname{IgAN}$ and clearly indicated a Th1 shift.

On the other hand, previous studies have suggested that in severe renal insufficiency there is an increase in Th2 cytokines and IL-4 in patients with IgAN compared with that in the controls $(27,53)$. In addition, Th2 cytokines induce poor glycosylation of $\operatorname{IgA}$ and involvement of these cytokines in Th2-dependent modifications of the sugar chain in the gastrointestinal mucosa and tonsils have also been demonstrated (53-55). Furthermore, the cytokine, IL-4, secreted by Th2 may play an important role in controlling glycosylation of the IgA1 HR (45) and renal fibrosis (46). A previous report demonstrated that $\mathrm{Th} 2$ predominance in $\operatorname{IgAN}$ was associated with chronic tonsillitis. In addition, $\alpha$-hemolytic streptococcus $(\alpha-H S)$ promoted a Th2-type immune response in tonsil mononuclear cells (TMCs) of IgAN (47). Furthermore, the loss of the encoding MAD homologue $4(\mathrm{Smad} 4)$ gene in $\mathrm{T}$ cells leads to the over-secretion of Th2 cytokines and the increase in the serum level of IgA. Moreover, Smad4 $4^{\text {co/co; Lck-cre }}$ mice showed a large amount of glomerular IgA deposition, increased albumin/creatinine ratio, abnormal glycosylation of IgA, complex of IgA with IgG1 and IgG2a, and polymeric IgA, all of which are known characteristics of human IgAN (56). However, a previous report demonstrated that the mRNA level of IL-2 in Th1 cells in patients with IgAN was also significantly associated with the mRNA level of IL-4 and IL-5 in Th2 cells (57). Cumulatively, these findings suggest that Th1/Th2 imbalance might play important roles in the pathogenesis of IgAN due to the Th1/Th2 polarity in the systemic immune response, which may induce the dysregulation of systemic tolerance, followed by B-lymphocyte proliferation and the production of abnormal IgA1. Notably, Thl cells may play a central pathogenetic role in the early phase of IgAN. By contrast, Th2 cells could be important in the later stages of disease progression. In addition, Thl cells and Th1 cytokines are associated with glomerular lesions, whereas Th2 cells and Th2 cytokine expression were associated with tubulointerstitial lesions. However, further validation studies are required to investigate the expression of Th1/Th2 cells in different stages of the disease.

\section{Th17 lymphocytes}

Th17 cells have been recently identified as a subtype of Th cells that produce IL-17 and play a role in nephritis, asthma and other autoimmune diseases (41,58-61). In addition, IL-17 is involved in the pathogenesis of IgAN. In a study of 32 patients with IgAN [16 patients with non-IgA mesangial proliferative glomerulonephritis (MsPGN) and 32 healthy subjects], Th17 cells were significantly increased in patients with IgAN compared with that in the healthy controls (62). Furthermore, Meng et al (21) demonstrated that the number of Th17 cells and the Th17:Treg ratio was increased in mice with IgAN, who were also revealed to have proteinuria and microscopic hematuria, mesangial hyperplasia, IgA deposition and high electron density deposition in the mesangial area. Moreover, the levels of the cytokines secreted by Th17 cells, including CCL20, IL-17A, IL-6 and IL-21 were all increased in the kidneys of mice with IgAN. In addition, different experimental groups were investigated [mice with IgAN; mice 
with $\operatorname{Ig} \mathrm{AN}$ infected using $\alpha$-HS, mice with $\operatorname{Ig} \mathrm{AN}$ treated with CCL20, and mice with IgAN infected using $\alpha-\mathrm{HS}$ and treated with CCL20) and it was revealed that the manifestations in mice with $\alpha$-HS-IgAN were more severe compared with that in mice with $\operatorname{IgAN}$, but was alleviated in the CCL20-treated groups. This study by Meng et al (21) suggests that $\alpha$-HS may aggravate renal damage in $\operatorname{IgAN}$ through the response to CCL20 secreted by Th17 cells. In an additional study of 60 biopsies from patients confirmed to have IgAN and 25 healthy controls, flow cytometric analysis revealed that the percentage of Th17 cells in the peripheral blood was markedly higher. Moreover, ELISA results indicated that the serum level of cytokine IL-17 was significantly higher in patients with IgAN compared with that in the control group (63). In addition, a previous study revealed that, compared with normal controls, patients with IgAN showed an increased number of Th17 cells. The serum levels of IL-17A and IL-21, secreted from Th17 cells, were increased in patients with $\operatorname{IgAN}$, and serum levels of IL-17A was associated with 24-h proteinuria. Moreover, the expression level of IL-17A was found in 34 out of 63 patients with IgAN at the renal tubule site. Compared with 29 patients without IL-17A expression, these patients had decreased renal function, increased proteinuria and more severe tubulointerstitial damage (64). Taken together, the aforementioned results suggest that Th17 cells and the serum level of IL-17 may be aggravating factors in $\operatorname{IgAN}$; however, to the best of our knowledge the mechanisms involved have not been determined. Furthermore, the sample size of the aforementioned studies was small, thus further studies are required with a much larger cohort of patients.

\section{TFH cells}

TFH cells are a distinct type of $\mathrm{CD}^{+} \mathrm{T}$ cell, which specifically regulate the antibody response. It is characterized by increased expression levels of numerous molecules, including Bcl-6, PD-1, ICOS, CD40-ligand (CD40L), and CXCR5, as well as IL-21 (65-67). With respect to the expression of CCR6 and CXCR3, 3 TFH subsets have been defined: CCR6 ${ }^{-} \mathrm{CXCR}^{+}$ TFH1 cells, CCR6-CXCR3- TFH2 cells, and CCR6 $^{+}$CXCR3 TFH17 cells (68). TFH cells function as crucial mediators of the humoral responses through direct interactions with B lymphocytes. Therefore, they are important factors in the quality of the antibody response after antigen stimulation. Over-secretion of TFH cells can lead to autoimmunity $(38,69,70)$, particularly in systemic lupus erythematosus (SLE), rheumatoid arthritis, and Sjögren's syndrome (66). In addition, a recent study revealed that, compared with healthy controls, significantly higher percentages of $\mathrm{CD}^{+} \mathrm{CXCR}^{+}, \mathrm{CD} 4^{+} \mathrm{CXCR} 5^{+} \mathrm{PD}-1^{+}$ TFH and $\mathrm{CD}^{+}{ }^{+} \mathrm{CXCR} 5^{+} \mathrm{ICOS}^{+}$cells, as well as higher serum levels of IL-2, IL-4, IL-10, IFN- $\gamma$, IL-17A and IL-21, were detected in patients with IgAN. Moreover, the percentages of $\mathrm{CD}^{+} \mathrm{CXCR}^{+} \mathrm{TFH}$ cells were negatively correlated with the values of estimated glomerular filtration rate (eGFR), and the percentage of $\mathrm{CD} 4^{+} \mathrm{CXCR} 5^{+} \mathrm{PD}-1^{+} \mathrm{TFH}$ cells was positively correlated with serum levels of IL-21, Gd-IgA1 and 24-h urinary proteins (23). Taken together, the results from the aforementioned studies indicate that TFH cells play an important role in $\operatorname{IgAN}$, which is due to the central role of TFH cells in antibody-associated immune response. However, the mechanism remains unclear. It is hypothesized that TFH cells provide a co-stimulation signal to activate antigen-specific autoreactive $\mathrm{B}$ lymphocytes by regulating the clonal selection of germinal center B cells and inducing high-affinity and long-lived plasma cell development and survival, resulting in high levels of autoantibody secretion $(71,72)$. Moreover, TFH cells can promote $B$ cell activation and plasma cell differentiation by producing IL-6 and IL-21 (73). As a result, the production of poorly galactosylated IgA1 autoantibodies interact with antigens to form an immune complex, which deposits on the renal mesangium, inducing several immune and pathological changes, eventually culminating in the development of $\operatorname{IgAN}(74,75)$. However, there is limited research regarding the role of TFH cells in the pathogenesis of IgAN and their potential as biomarkers. Thus, further validation studies are required.

\section{Tregs}

Tregs, defined as $\mathrm{CD} 4{ }^{+} \mathrm{CD} 25^{+} \mathrm{FoxP} 3{ }^{+}$cells, are well-known to be a subset of $\mathrm{T}$ lymphocytes that play a central role in developing tolerance to autoantigens through direct cell contact or by producing anti-inflammatory cytokines, such as TGF- $\beta 1$ and IL-10 (76,77). A recent study revealed that patients with IgAN had decreased numbers of tonsillar Tregs, which was negatively correlated with the number of cells producing dimeric IgA (78). In addition, another study found that, in patients with Henoch-Schönlein purpura and primary IgAN, mRNA expression levels of TGF- $\beta 1$ and FoxP3 were significantly lower compared with that in healthy controls (79). Furthermore, a recent study has shown that, compared with normal controls, patients with IgAN had a decreased number of the CD45RA-FoxP3 ${ }^{\text {high }}$ aTreg cells and amount of IL-10. Moreover, the numbers of aTreg cells were negatively correlated with eGFR and 24-h proteinuria. Foxp $3^{+}$monocyte infiltration was observed in the renal interstitium of patients with $\operatorname{Ig} \mathrm{AN}$, particularly in patients with $>25 \%$ tubular atrophy/interstitial fibrosis (64). In an additional study, it was revealed that the levels of proteins in the urine decreased and the number of red blood cells were improved after $\mathrm{CD} 4^{+} \mathrm{CD} 25^{+} \mathrm{T}$ cells were infused into the IgAN rat model. Moreover, renal pathological examination revealed that there was an improvement in renal tissue. Immunohistochemistry analysis of $\operatorname{IgA}$ revealed that the deposition of IgA in the mesangial cells was lower compared with that in a rat IgAN model (80). Yang et al (81) demonstrated that the number of iTregs in patients with IgAN was significantly lower compared with that in healthy controls. However, the nTreg levels did not significantly change. In addition, the expression levels of TGF- $\beta$ and IL-10 in patients with IgAN were lower, whereas those of IL-17 were higher compared with that in healthy controls (81). Furthermore, in a study of 35 patients with IgAN and 35 patients without renal disease, $\mathrm{CD} 4{ }^{+} \mathrm{CD} 25^{+}$Treg cells were significantly lower in patients with IgAN compared with that in the controls before tonsillectomy, and were also negatively correlated with blood urea nitrogen, IL-4 levels and proteinuria, positively correlated with eGFR, and gradually decreased as the severity of renal histology increased. Furthermore, serum levels of IgA, IL-2, IL-4 and IL-6 were increased while the number of $\mathrm{CD} 4{ }^{+} \mathrm{CD} 25^{+}$Treg cells were decreased in patients with 
IgAN. After tonsillectomy, serum levels of IgA, IL-2, IL-4, IL-6, urine protein and urine erythrocytes were decreased, while the levels of $\mathrm{CD} 4{ }^{+} \mathrm{CD} 25^{+}$Treg cells were significantly increased but were still lower compared with that in the control groups (22). Taken together, the aforementioned studies have shown that Treg cells are associated with IgAN and increasing Treg cells in patients with IgAN may lead to clinical improvement. Adoptive transfer of autologous or donor-derived Tregs represents an exciting immunotherapeutic strategy for patients with IgAN. However, to the best of our knowledge experiments have only been performed in rat models of IgAN. Further studies are urgently required to address this limitation.

\section{Th22 cells}

The newly discovered Th cell 22 (Th22) is a subset of $\mathrm{CD}^{+} \mathrm{T}$ cells, which is distinguished by analyzing the gene expression levels of $\mathrm{C}-\mathrm{C}$ chemokine receptor type 4 (CCR4), CCR6 and CCR10, which were first described in 2009 by Trifari et al (82). These cells are characterized by the secretion of different types of effector cytokines, including IL-22, IL-13 and TNF- $\alpha$ (82). The abundance of Th22 cells and levels of the IL-22 cytokine are increased and are positively correlated with inflammatory and autoimmune disorders, such as psoriasis, SLE and rheumatoid arthritis $(83,84)$. A recent study revealed that the numbers of Th22 cells and plasma levels of IL-22 in patients with IgAN were significantly higher compared with that in patients with non-IgA MsPGN and normal controls. There was a positive correlation between the numbers of Th22 cells and plasma levels IL-22 in patients with IgAN. In addition, there was a significant positive correlation between Th22 and Th17 cells in patients with IgAN. Moreover, the number of Th22 cells in patients with IgAN with proteinuria was higher compared with that in patients with IgAN without proteinuria (62). Meanwhile, in a recent exploratory study of the number of Th22 cells in an IgAN mouse model and the effect of losartan and dexamethasone on Th22 cells was investigated. It was found that both drugs differentially reduced the number of Th22 cells after 1 month, and mesangial cell proliferation was also improved. Meanwhile, the expression of IL-22, CCR10 and CCL27 was decreased following treatment with either drug (85). In summary, based on the aforementioned research, similar to Th17 cells, Th22 cells and secreted serum IL-22 levels may be exacerbating factors in patients with IgAN. However, there is limited research on the role of Th22 cells in the pathogenesis of IgAN, and further studies are required to clarify the role of $\mathrm{Th} 22$ cells in the pathogenesis and progression of IgAN.

\section{9. $\mathrm{CD8}^{+}$cells}

With the assistance of $\mathrm{CD} 4^{+} \mathrm{T}$ cells, $\mathrm{CD} 8^{+} \mathrm{T}$ cells form part of the adaptive immune response, functioning to effectively clear viruses (86). The role of $\mathrm{CD} 4{ }^{+} \mathrm{T}$ cells in the progression of IgAN has been aforementioned. Similarly, the role of CD8 ${ }^{+}$ $\mathrm{T}$ cells in the progression of $\operatorname{IgAN}$ was also reported (24). Tomino et al (87) reported that the most prominent glomerular-infiltrating cell type was $\mathrm{CD}^{+} \mathrm{T}$ cells in $\mathrm{IgAN}$, and an immunoregulatory mechanism involving $\mathrm{CD}^{+} \mathrm{T}$ cells might be one of the exacerbating factors in patients with IgAN.
Sabadini et al (88) reported that the degree of interstitial CD8 ${ }^{+}$ lymphocyte infiltration was correlated with the severity of interstitial fibrosis and renal impairment. Shimamine et al (89) reported that anti-CD8 T-lymphocyte treatment produced a protective effect against mesangial injury in ddY mice, an animal model of spontaneous IgAN. In another study, 20 children with IgAN who were followed for $>5$ years were divided into the progressive $(\mathrm{n}=5)$ and non-progressive groups $(\mathrm{n}=15)$. It was revealed that the number of $\mathrm{CD}^{+} \mathrm{T}$ cells in the glomeruli and in the interstitium was higher in the progressive group compared with that in the non-progressive group. In addition, glomerular $\alpha$-smooth muscle actin staining, which is associated with mesangial cell proliferation $(90,91)$, was more intense in the progressive group compared with that in the non-progressive group. Moreover, urinary protein and the degree of histological changes were also higher in the progressive group compared with that in the non-progressive group. However, among these markers, the number of glomerular $\mathrm{CD} 8^{+} \mathrm{T}$ cells was the most marked difference between the two groups (92). Meanwhile, a recent study revealed a greater distribution of CX3CR1-positive cells in the interfollicular area of tonsils in patients with IgAN compared with that in patients with non-IgAN. CX3CR1-positive cells were also found in the affected renal glomerulus of patients with IgAN. In addition, the expression level of CX3CR 1 on tonsillar CD ${ }^{+}$ cells, cytotoxic effector lymphocytes that includes natural killer and terminally differentiated cytotoxic $\mathrm{T}$ cells $(93,94)$, which potentially express CD8 $(94,95)$, was significantly higher in patients with IgAN. Furthermore, in this study, CpG-oligodeoxynucleotides enhanced the expression of $\mathrm{CD} 8^{+}$ cells in patients with IgAN. The chemotactic response of tonsillar mononuclear cells to fractalkine was significantly higher in patients with IgAN. The expression of CX3CR1 in the peripheral blood $\mathrm{CD}^{+}$cells in patients with IgAN was significantly higher and decreased after tonsillectomy, along with the disappearance of hematuria (24). Taken together, the aforementioned studies suggest that $\mathrm{CD} 8^{+} \mathrm{T}$ cells might be one of the exacerbating factors in patients with IgAN. In addition, the number of glomerular $\mathrm{CD} 8^{+} \mathrm{T}$ cells may be a sensitive predictor of disease progression in IgAN. However, to date, there is limited research on the role of $\mathrm{CD} 8^{+} \mathrm{T}$ cells in the pathogenesis of IgAN, and further studies are required to clarify the location of $\mathrm{CD}^{+}$cells and pathophysiological role of $\mathrm{CD}^{+} \mathrm{T}$ cells in IgAN.

\section{Imbalance of $T$ cell subsets as a target for the treatment of $\operatorname{IgAN}$}

In addition to their general role in IgAN, which is associated with the severity of renal damage and disease progression, several studies have identified the imbalance of T cell subsets as a target for the treatment of IgAN (96). Hyun et al (97) reported that, in ddY mice with high levels of IgA (hyperserum IgA; HIGA), after injecting adipose-derived stem cells (ASCs), which were reported to prevent tissue damage through immunomodulating effects (98), 24-h proteinuria was markedly decreased in all ASC-treated groups. In addition, mesangial proliferation and glomerulosclerosis were markedly decreased in most ASC-treatment groups. Furthermore, the beneficial effects of ASC treatment in IgAN occurred via paracrine 
mechanisms that modulate the Th1/Th2 cytokine balance, as ASC therapy significantly decreased Th1 cytokine activity in the kidney and caused a shift to Th2 responses in T cells from the spleen. In addition, conditioned media from ASCs abrogated aggregated IgA-induced Th1 cytokine production in cultured HIGA mesangial cells. Chen et al (99) reported that, in rats with $\operatorname{IgAN}$, which were randomly divided into either the model group, Tripterygium wilfordii glycoside (TWG) treatment group, or the prednisone treatment group, treatment with TWG and prednisone significantly reduced urine protein levels and urine red blood cells at $24 \mathrm{~h}$ and reduced IgA deposition in renal tissue. Furthermore, TWG showed therapeutic effects in IgAN rats and may regulate the immune balance of Th17 and Tregs as they significantly decreased the serum levels of IL-17 and increased the number of Tregs in the blood. Xiao et al (85) reported that, in a mouse model of IgAN, losartan and dexamethasone differentially decreased the number of Th22 cells after 1 month, and mesangial cell proliferation was also improved. Meanwhile, Zhang et al (23) reported that treatment with prednisone significantly reduced the number of $\mathrm{CD} 4{ }^{+} \mathrm{CXCR} 5^{+}$and $\mathrm{CD} 4{ }^{+} \mathrm{CXCR}^{+} \mathrm{PD}-1^{+} \mathrm{TFH}$ cells and the serum level of IL-21, but the treatment increased IL-4 and IL-10 in patients with IgAN. Furthermore, in another study it was revealed that, after $\mathrm{CD} 4{ }^{+} \mathrm{CD} 25^{+} \mathrm{T}$ cells were injected into the $\operatorname{Ig} \mathrm{AN}$ rat model, levels of urine protein and red blood cells were improved. Moreover, renal pathological examination revealed that renal tissue was improved (77). Currently, patients with IgAN are typically treated with corticosteroids and other immunosuppressants clinically. Based on the aforementioned research, it is possible that the immunosuppressants have therapeutic effects on IgAN by regulating the imbalance of $\mathrm{T}$ cell subsets. Notably, Tregs may be used for immunotherapy in $\operatorname{Ig} \mathrm{AN}$ by suppressing exuberant immune system activation and promoting immunological tolerance. Adoptive transfer of autologous or donor-derived Tregs represents a promising immunotherapeutic strategy for IgAN $(80,37)$. Overall, statistical evidence for the involvement of the imbalance of $\mathrm{T}$ cell subsets as a target for the treatment with $\operatorname{IgAN}$ is speculative, rather than concrete. Further validation studies in this area are required.

\section{Future perspectives}

Over the past decade, evidence has emerged that cellular immunity plays important roles in the pathogenesis of $\operatorname{Ig} \mathrm{AN}$. Notably, the identification of specific T cells and cell cytokines involved in the pathogenesis and progression of IgAN highlights the imbalance of $\mathrm{T}$ cell subsets as new therapeutic targets and biomarkers for the treatment and monitoring of the disease. Currently, corticosteroids and other immunosuppressants have shown therapeutic effects on IgAN, possibly by regulating the imbalance of $\mathrm{T}$ cell subsets. Furthermore, Tregs may be used for immunotherapy of IgAN by adoptive transfer of $\mathrm{CD} 4{ }^{+} \mathrm{CD} 25^{+}$cells. However, the potential application of $\mathrm{T}$ cellular immunity quantification to the clinical care of patients with IgAN remains in the early stages of development, with available evidence limited to small-scale studies.

Regarding the clinically feasible imbalance of $\mathrm{T}$ cell subsets as new therapeutic targets and biomarkers for the treatment and monitoring of disease to succeed, further studies are urgently required in numerous areas. Notably, the diagnostic role of specific $\mathrm{T}$ cells and cell cytokine levels have not been confirmed in studies of adequate sample size, different patient populations and in patients with other forms of glomerulonephritis and CKD as controls. As a tool for risk stratification and disease monitoring, the relationship between all $\mathrm{T}$ cell subsets and the degree of histological damage has not been investigated, and data on the association between different $\mathrm{T}$ cell subsets and the rate of decline in renal function are limited. No research groups have studied the association between specific $\mathrm{T}$ cells, cell cytokine levels and 'hard' renal end points (such as end-stage renal disease and doubling of serum creatinine). In addition, no data exist on the possible role of the serial monitoring of specific T cells, cell cytokine levels and the association between these $\mathrm{T}$ cell subsets and disease changes at different stages. Nonetheless, the investigation of specific $\mathrm{T}$ cells and cell cytokine levels on disease progression, particularly in the early phase, should be investigated further to validate its role in risk stratification and monitoring of patients with $\operatorname{IgAN}$.

\section{Conclusions}

Although a limited number of studies exist, T cell subsets have been identified as potentially relevant to the pathogenesis of IgAN. All of the studies discussed in the present review have shed light on the pathogenesis of IgAN, nevertheless they all share similar methodological deficiencies. Specifically, all have small sample sizes, and their results have undergone limited adjustment for multiple testing or potential clinical confounding factors. A number of the studies did not have proper disease controls to determine whether the findings are specific for IgAN or are generic markers of kidney damage. In addition, no data exist on all $\mathrm{T}$ cell subsets, comparisons of all $\mathrm{T}$ cell subsets involved in the pathogenesis and progression of IgAN, and serial monitoring of these $\mathrm{T}$ cell subset changes at different stages of $\operatorname{IgAN}$. Further validation studies, preferably in different stages of the disease and using several different populations of patients, are required before advancements can be made and the therapeutic implication of these T-cell subsets can be used. In a word, the imbalance of T cell differentiation leads to abnormal proliferation of B lymphocytes, which leads to more secretion of Gd-IgA1 and ultimately to the occurrence of IgA nephropathy.

\section{Acknowledgements}

Not applicable.

\section{Funding}

This study was supported by Shanghai Health and Planning Commission Scientific Research Foundation (no. 20184Y0040) and Research on Natural Science in Minhang District of Shanghai (no. 2018MHZ069) and the National Natural Science Foundation of China (no. 81774060).

\section{Availability of data and materials}

Not applicable. 


\section{Authors' contributions}

YT, HD, PH and XX were all responsible for the search and review of the cited literature and writing of the manuscript. All authors read and approved the final manuscript.

\section{Ethics approval and consent to participate}

Not applicable.

\section{Patient consent for publication}

Not applicable.

\section{Competing interests}

The authors declare that they have no competing interests.

\section{References}

1. Ohyama Y, Yamaguchi H, Nakajima K, Mizuno T, Fukamachi Y, Yokoi Y, Tsuboi N, Inaguma D, Hasegawa M, Renfrow MB, et al: Analysis of O-glycoforms of the IgA1 hinge region by sequential deglycosylation. Sci Rep 10: 671, 2020.

2. Kiryluk K, Li Y, Moldoveanu Z, Suzuki H, Reily C, Hou P, Xie J, Mladkova N, Prakash S, Fischman C, et al: GWAS for serum galactose-deficient $\operatorname{IgA} 1$ implicates critical genes of the O-glycosylation pathway. PLoS Genet 13: e1006609, 2017.

3. Wang X, Li T, Si R, Chen J, Qu Z and Jiang Y: Increased frequency of PD- $1^{\text {hi }} \mathrm{CXCR}^{-} \mathrm{T}$ cells and $\mathrm{B}$ cells in patients with newly diagnosed IgA nephropathy. Sci Rep 10: 492, 2020.

4. Xing Y, Li L, Zhang Y, Wang F, He D, Liu Y, Jia J, Yan T and Lin S: C1GALT1 expression is associated with galactosylation of IgA1 in peripheral B lymphocyte in immunoglobulin a nephropathy. BMC Nephrol 21: 18, 2020.

5. Yeo SC, Cheung CK and Barratt J: New insights into the pathogenesis of IgA nephropathy. Pediatr Nephrol 33: 763-777, 2018.

6. Perše M and Večerić-Haler Ž: The role of $\operatorname{IgA}$ in the pathogenesis of IgA nephropathy. Int J Mol Sci 20: E6199, 2019.

7. Knoppova B, Reily C, Maillard N, Rizk DV, Moldoveanu Z, Mestecky J, Raska M, Renfrow MB, Julian BA and Novak J: The origin and activities of IgA1-containing immune complexes in IgA nephropathy. Front Immunol 7: 117, 2016.

8. Hu S, Bao H, Xu X, Zhou X, Qin W, Zeng C and Liu Z: Increased miR-374b promotes cell proliferation and the production of aberrant glycosylated IgA1 in B cells of IgA nephropathy. FEBS Lett 589: 4019-4025, 2015.

9. Sallustio F, Curci C, Di Leo V, Gallone A, Pesce F and Gesualdo L: A new vision of IgA nephropathy: The missing link. Int J Mol Sci 21: E189, 2019.

10. Ito S, Misaki T, Naka S, Wato K, Nagasawa $Y$, Nomura R, Otsugu M, Matsumoto-Nakano M, Nakano K, Kumagai H and Oshima N: Specific strains of Streptococcus mutans, a pathogen of dental caries, in the tonsils, are associated with IgA nephropathy. Sci Rep 9: 20130, 2019.

11. Makita Y, Suzuki H, Kano T, Takahata A, Julian BA, Novak J and Suzuki Y: TLR9 activation induces aberrant IgA glycosylation via APRIL- and IL-6-mediated pathways in IgA nephropathy. Kidney Int 97: 340-349, 2020.

12. Suzuki H, Fan R, Zhang Z, Brown R, Hall S, Julian BA, Chatham WW, Suzuki Y, Wyatt RJ, Moldoveanu Z, et al: Aberrantly glycosylated IgA1 in IgA nephropathy patients is recognized by IgG antibodies with restricted heterogeneity. J Clin Invest 119: 1668-1677, 2009.

13. Xu BY, Meng SJ, Shi SF, Liu LJ, Lv JC, Zhu L and Zhang H: MicroRNA-21-5p participates in IgA nephropathy by driving $\mathrm{T}$ helper cell polarization. J Nephrol: Dec 20, 2019 doi. org/10.1007/s40620-019-00682-3 (Epub ahead of print).

14. Serino G, Sallustio F, Cox SN, Pesce F and Schena FP: Abnormal miR-148b expression promotes aberrant glycosylation of IgA1 in IgA nephropathy. J Am Soc Nephrol 23: 814-824, 2012.

15. Batra A, Smith AC, Feehally J and Barratt J: T-cell homing receptor expression in IgA nephropathy. Nephrol Dial Transplant 22: 2540-2548, 2007
16. Enya T, Miyazawa T, Miyazaki K, Oshima R, Morimoto Y, Okada M, Takemura T and Sugimoto K: Pathologic tonsillar findings similar to $\operatorname{Ig}$ A nephropathy and the role of tonsillectomy in a patient with nephrotic syndrome. BMC Nephrol 20: 381, 2019.

17. Meng H, Ohtake H, Ishida A, Ohta N, Kakehata S and Yamakawa M: IgA production and tonsillar focal infection in IgA nephropathy. J Clin Exp Hematop 52: 161-170, 2012.

18. Yang Y, Liu K, Chen Y, Gong Y and Liang Y: Indoleamine 2,3-dioxygenase (IDO) regulates Th17/Treg immunity in experimental IgA nephropathy. Folia Biol (Praha) 65: 101-108, 2019.

19. Yamada K, Kobayashi N, Ikeda T, Suzuki Y, Tsuge T, Horikoshi S, Emancipator SN and Tomino Y: Down-regulation of core 1 beta1,3-galactosyltransferase and Cosmc by Th2 cytokine alters O-glycosylation of IgA1. Nephrol Dial Transplant 25: 3890-3897, 2010.

20. Suzuki H, Suzuki Y, Aizawa M, Yamanaka T, Kihara M, Pang H, Horikoshi S and Tomino Y: Th1 polarization in murine IgA nephropathy directed by bone marrow-derived cells. Kidney Int 72: 319-327, 2007.

21. Meng T, Li X, Ao X, Zhong Y, Tang R, Peng W, Yang J, Zou M and Zhou Q: Hemolytic Streptococcus may exacerbate kidney damage in IgA nephropathy through CCL20 response to the effect of Th17 cells. PLoS One 9: e108723, 2014.

22. Huang H, Sun W, Liang Y, Peng Y, Long XD, Liu Z, Wen X, Jia M, Tian R, Bai C and Li C: CD4 (+)CD 25 (+)Treg cells and IgA nephropathy patients with tonsillectomy: A clinical and pathological study. Int Urol Nephrol 46: 2361-2369, 2014.

23. Zhang L, Wang Y, Shi X, Zou $\mathrm{H}$ and Jiang Y: A higher frequency of $\mathrm{CD}^{+}{ }^{+} \mathrm{CXCR}^{+} \mathrm{T}$ follicular helper cells in patients with newly diagnosed IgA nephropathy. Immunol Lett 158: 101-108, 2014.

24. Otaka R, Takahara M, Ueda S, Nagato T, Kishibe K, Nomura K, Katada A, Hayashi T and Harabuchi Y: Up-regulation of CX3CR1 on tonsillar CD8-positive cells in patients with IgA nephropathy. Hum Immunol 78: 375-383, 2017.

25. Chen X, Tang Y, Zhang Y, Zhuo M, Tang Z, Yu Y and Zang G: Tapasin modification on the intracellular epitope HBcAg18-27 enhances HBV-specific CTL immune response and inhibits hepatitis B virus replication in vivo. Lab Invest 94: 478-490, 2014.

26. Wu YJ, Song YN, Geng XR, Ma F, Mo LH, Zhang XW, Liu DB, Liu ZG and Yang PC: Soluble CD83 alleviates experimental allergic rhinitis through modulating antigen-specific Th2 cell property. Int J Biol Sci 16: 216-227, 2020.

27. Tortajada A, Gutierrez E, Pickering MC, Praga Terente M and Medjeral-Thomas N: The role of complement in IgA nephropathy. Mol Immunol 114: 123-132, 2019.

28. Shao F, Zheng P, Yu D, Zhou Z and Jia L: Follicular helper T cells in type 1 diabetes. FASEB J 34: 30-40, 2020.

29. Gao Y, Jin H, Nan D, Yu W, Zhang J, Yang Y, Hou R, Qin R, Hao H, Sun Y and Tian W: The role of T follicular helper cells and $\mathrm{T}$ follicular regulatory cells in the pathogenesis of autoimmune hemolytic anemia. Sci Rep 9: 19767, 2019.

30. Oestreich KJ and Weinmann AS: Transcriptional mechanisms that regulate $\mathrm{T}$ helper 1 cell differentiation. Curr Opin Immunol 24: 191-195, 2012.

31. Wang Q, Li J, Yu TS, Liu Y, Li K, Liu S, Liu Y, Feng Q, Zhang L, Li GS, et al: Disrupted balance of $\mathrm{CD}^{+} \mathrm{T}$-cell subsets in bone marrow of patients with primary immune thrombocytopenia. Int J Biol Sci 15: 2798-2814, 2019.

32. Magen A, Nie J, Ciucci T, Tamoutounour S, Zhao Y, Mehta M, Tran B, McGavern DB, Hannenhalli S and Bosselut R: Single-cell profiling defines transcriptomic signatures specific to tumor-reactive versus virus-responsive $\mathrm{CD} 4^{+} \mathrm{T}$ cells. Cell Rep 29: 3019-3032.e6, 2019.

33. Tang Y, Chen X, Zhang Y, Tang Z, Zhuo M, Li D, Wang P,Zang G and $\mathrm{Yu}$ Y: Fusion protein of tapasin and hepatitis B core antigen 18-27 enhances $T$ helper cell type $1 / 2$ cy tokine ratio and antiviral immunity by inhibiting suppressors of cytokine signaling family members $1 / 3$ in hepatitis B virus transgenic mice. Mol Med Rep 9: 1171-1178, 2014.

34. Edwards ESJ, Bosco JJ, Aui PM, Stirling RG, Cameron PU, Chatelier J, Hore-Lacy F, O'Hehir RE and van Zelm MC: Predominantly antibody-deficient patients with non-infectious complications have reduced naive B, Treg, Th17, and Tfh17 cells. Front Immunol 10: 2593, 2019.

35. Shea-Donohue T, Fasano A, Smith A and Zhao A: Enteric pathogens and gut function: Role of cytokines and STATs. Gut Microbes 1: 316-324, 2010. 
36. Blokland SLM, van Vliet-Moret FM, Hillen MR, Pandit A, Goldschmeding R, Kruize AA, Bouma G, van Maurik A, Olek S, Hoffmueller U, et al: Epigenetically quantified immune cells in salivary glands of Sjögren's syndrome patients: A novel tool that detects robust correlations of $\mathrm{T}$ follicular helper cells with immunopathology. Rheumatology (Oxford) 59: 335-343, 2020.

37. Singer BD, King LS and D'Alessio FR: Regulatory T cells as immunotherapy. Front Immunol 5: 46, 2014.

38. Read KA, Powell MD and Oestreich KJ: T follicular helper cell programming by cytokine-mediated events. Immunology 149: 253-261, 2016.

39. Phillips S, Chokshi S, Riva A, Evans A, Williams R and Naoumov NV: CD8(+) T cell control of hepatitis B virus replication: Direct comparison between cytolytic and noncytolytic functions. J Immunol 184: 287-295, 2010.

40. Tang YY, Tang ZH, Zhang Y, Zhuo M, Zang GQ, Chen XH and Yu YS: The fusion protein of CTP-HBcAg18-27-tapasin mediates the apoptosis of CD8(+)T cells and CD8(+) T cell response in HLA-A2 transgenic mice. Hepat Mon 14: e16161, 2014.

41. Krebs CF and Steinmetz OM: $\mathrm{CD}^{+} \mathrm{T}$ cell fate in glomerulonephritis: A tale of Th1, Th17, and novel Treg subtypes. Mediators Inflamm 2016: 5393894, 2016.

42. Habura I, Fiedorowicz K, Woźniak A, Idasiak-Piechocka I, Kosikowski P and Oko A: IgA nephropathy associated with coeliac disease. Cent Eur J Immunol 44: 106-108, 2019.

43. Suzuki H and Suzuki Y: Murine models of human IgA nephropathy. Semin Nephrol 38: 513-520, 2018

44. Tsuruga K, Oki E, Aizawa-Yashiro T, Yoshida H, Imaizumi T and Tanaka H: Potential $\mathrm{Th}^{1} / \mathrm{Th} 2$ predominance in children with newly diagnosed IgA nephropathy. Acta Paediatr 99: 1584-1586, 2010.

45. He L, Peng Y, Liu H, Yin W, Chen X, Peng X, Shao J, Liu Y and Liu F: Activation of the interleukin-4/signal transducer and activator of transcription 6 signaling pathway and homeodomain-interacting protein kinase 2 production by tonsillar mononuclear cells in IgA nephropathy. Am J Nephrol 38 321-332, 2013

46. Liu L, Kou P, Zeng Q, Pei G, Li Y, Liang H, Xu G and Chen S: CD4+ T Lymphocytes, especially Th2 cells, contribute to the progress of renal fibrosis. Am J Nephrol 36: 386-396, 2012.

47. He L, Peng Y, Liu H, Yin W, Chen X, Peng X, Shao J, Liu Y and Liu F: Th1/Th2 polarization in tonsillar lymphocyte form patients with IgA nephropathy. Ren Fail 36: 407-412, 2014.

48. Takahara M, Nagato T, Nozaki Y, Kumai T, Katada A, Hayashi T and Harabuchi Y: A proliferation-inducing ligand (APRIL) induced hyper-production of $\operatorname{Ig} \mathrm{A}$ from tonsillar mononuclear cells in patients with IgA nephropathy. Cell Immunol 341: 103925, 2019.

49. Glassock RJ: Mortality risk in IgA nephropathy. J Am Soc Nephrol 30: 720-722, 2019.

50. Sallustio F, Serino G, Cox SN, Dalla Gassa A, Curci C, De Palma G Banelli B, Zaza G, Romani M and Schena FP: Aberrantly methylated DNA regions lead to low activation of CD4+ T-cells in IgA nephropathy. Clin Sci (Lond) 130: 733-746, 2016.

51. Jang YS, Seo GY, Lee JM, Seo HY, Han HJ, Kim SJ, Jin BR, Kim HJ, Park SR, Rhee KJ, et al: Lactoferrin causes $\operatorname{IgA}$ and IgG2b isotype switching through betaglycan binding and activation of canonical TGF- $\beta$ signaling. Mucosal Immunol 8: 906-917, 2015.

52. Seo GY, Jang YS, Kim HA, Lee MR, Park MH, Park SR, Lee JM, Choe J and Kim PH: Retinoic acid, acting as a highly specific IgA isotype switch factor, cooperates with TGF- $\beta 1$ to enhance the overall IgA response. J Leukoc Biol 94: 325-335, 2013.

53. Bai L, Li H, Li J, Song J, Zhou Y, Liu B, Lu R, Zhang P, Chen J, Chen D, et al: Immunosuppressive effect of artemisinin and hydroxychloroquine combination therapy on $\operatorname{IgA}$ nephropathy via regulating the differentiation of CD4+ T cell subsets in rats. Int Immunopharmacol 70: 313-323, 2019.

54. Ruszkowski J, Lisowska KA, Pindel M, Heleniak Z, Debska-Ślizień A and Witkowski JM: T cells in IgA nephropathy: Role in pathogenesis, clinical significance and potential therapeutic target. Clin Exp Nephrol 23: 291-303, 2019.

55. Xiao J, Wang M, Xiong D, Wang Y, Li Q, Zhou J and Chen Q TGF- $\beta 1$ mimics the effect of IL- 4 on the glycosylation of IgA1 by downregulating core $1 \beta 1,3$-galactosyltransferase and Cosmc. Mol Med Rep 15: 969-974, 2017.

56. Inoshita H, Kim BG, Yamashita M, Choi SH, Tomino Y, Letterio JJ and Emancipator SN: Disruption of Smad4 expression in $\mathrm{T}$ cells leads to IgA nephropathy-like manifestations. PLoS One 8: e78736, 2013.
57. Lai KN, Ho RT, Lai CK, Chan $\mathrm{CH}$ and Li PK: Increase of both circulating Th1 and Th2 T lymphocyte subsets in IgA nephropathy. Clin Exp Immunol 96: 116-121, 1994.

58. Kagami S: IL-23 and Th17 cells in infections and psoriasis. Nihon Rinsho Meneki Gakkai Kaishi 34: 13-19, 2011 (In Japanese).

59. Thomi R, Schlapbach C, Yawalkar N, Simon D, Yerly D and Hunger RE: Elevated levels of the antimicrobial peptide LL-37 in hidradenitis suppurativa are associated with a Th1/Th17 immune response. Exp Dermatol 27: 172-177, 2018.

60. Waite JC and Skokos D: Th17 response and inflammatory autoimmune diseases. Int J Inflamm 2012: 819467, 2012.

61. Fu Y, Liu S, Wang Y, Ren F, Fan X, Liang J, Liu C, Li J, Ju Y and Chang Z: GdX/UBL4A-knockout mice resist collagen-induced arthritis by balancing the population of $\mathrm{T}_{\mathrm{h}} 1 / \mathrm{T}_{\mathrm{h}} 17$ and regulatory T cells. FASEB J 33: 8375-8385, 2019

62. Peng Z, Tian J, Cui X, Xian W, Sun H, Li E, Geng L, Zhang L and Zhao P: Increased number of Th22 cells and correlation with Th17 cells in peripheral blood of patients with $\operatorname{IgA}$ nephropathy. Hum Immunol 74: 1586-1591, 2013.

63. Yang L, Zhang X, Peng W, Wei M and Qin W: MicroRNA-155induced T lymphocyte subgroup drifting in IgA nephropathy. Int Urol Nephrol 49: 353-361, 2017.

64. Lin FJ, Jiang GR, Shan JP, Zhu C, Zou J and Wu XR: Imbalance of regulatory T cells to Th17 cells in IgA nephropathy. Scand J Clin Lab Invest 72: 221-229, 2012.

65. Jain S, Stock A, Macian F and Putterman C: A distinct T follicular helper cell subset infiltrates the brain in murine neuropsychiatric lupus. Front Immunol 9: 487, 2018.

66. Gowthaman U, Chen JS, Zhang B, Flynn WF, Lu Y, Song W, Joseph J, Gertie JA, Xu L, Collet MA, et al: Identification of a $\mathrm{T}$ follicular helper cell subset that drives anaphylactic IgE. Science 365: eaaw6433, 2019.

67. Nus M, Sage AP, Lu Y, Masters L, Lam BYH, Newland S, Weller S, Tsiantoulas D, Raffort J, Marcus D, et al: Marginal zone B cells control the response of follicular helper $\mathrm{T}$ cells to a high-cholesterol diet. Nat Med 23: 601-610, 2017.

68. Grados A, Ebbo M, Piperoglou C, Groh M, Regent A, Samson M, Terrier B, Loundou A, Morel N, Audia S, et al: T cell polarization toward $\mathrm{T}_{\mathrm{H}} 2 / \mathrm{T}_{\mathrm{FH}} 2$ and $\mathrm{T}_{\mathrm{H}} 17 / \mathrm{T}_{\mathrm{FH}} 17$ in patients with IgG4-related disease. Front Immunol 8: 235, 2017.

69. Webb LMC and Linterman MA: Signals that drive T follicular helper cell formation. Immunology 152: 185-194, 2017.

70. Makiyama A, Chiba A, Noto D, Murayama G, Yamaji K, Tamura N and Miyake S: Expanded circulating peripheral helper T cells in systemic lupus erythematosus: Association with disease activity and B cell differentiation. Rheumatology (Oxford) 58: 1861-1869, 2019.

71. Zhang Y, Long X and Wang X: Primary T-cell transduction to study follicular helper T-cell differentiation. Methods Mol Biol 2111: 115-126, 2020.

72. Patakas A, Platt AM, Butcher JP, Maffia P, McInnes IB, Brewer JM, Garside P and Benson RA: Putative existence of reciprocal dialogue between Tfh and B cells and its impact on infectious and autoimmune disease. Immunol Lett 138: 38-46, 2011.

73. Chen Y, Yu M, Zheng Y, Fu G, Xin G, Zhu W, Luo L, Burns R, Li QZ, Dent AL, et al: CXCR5 ${ }^{+} \mathrm{PD}-1^{+}$follicular helper CD8 T cells control B cell tolerance. Nat Commun 10: 4415, 2019.

74. Suzuki H, Kiryluk K, Novak J, Moldoveanu Z, Herr AB, Renfrow MB, Wyatt RJ, Scolari F, Mestecky J, Gharavi AG and Julian BA: The pathophysiology of IgA nephropathy. J Am Soc Nephrol 22: 1795-1803, 2011

75. Wyatt RJ and Julian BA: IgA nephropathy. N Engl J Med 368: 2402-2414, 2013.

76. Charbonnier LM, Cui Y, Stephen-Victor E, Harb H, Lopez D, Bleesing JJ, Garcia-Lloret MI, Chen K, Ozen A, Carmeliet P, et al: Functional reprogramming of regulatory $\mathrm{T}$ cells in the absence of Foxp3. Nat Immunol 20: 1208-1219, 2019.

77. Cormican S and Griffin MD: The complex role of interleukin 6 in regulating T-cell responses during acute glomerulonephritis. J Am Soc Nephrol 30: 1341-1344, 2019.

78. Huang H, Peng Y, Liu H, Yang X and Liu F: Decreased $\mathrm{CD} 4{ }^{+} \mathrm{CD} 25^{+}$cells and increased dimeric IgA-producing cells in tonsils in IgA nephropathy. J Nephrol 23: 202-209, 2010.

79. Donadio ME, Loiacono E, Peruzzi L, Amore A, Camilla R, Chiale F, Vergano L, Boido A, Conrieri M, Bianciotto M, et al: Toll-like receptors, immunoproteasome and regulatory $\mathrm{T}$ cells in children with Henoch-Schönlein purpura and primary IgA nephropathy. Pediatr Nephrol 29: 1545-1551, 2014.

80. Shen BL, Qu QS, Miao SZ, Liu BL, Liu RY and Gu DF: Study on the effects of regulatory T cells on renal function of IgAN rat model. Eur Rev Med Pharmacol Sci 19: 284-288, 2015. 
81. Yang S, Chen B, Shi J, Chen F, Zhang J and Sun Z: Analysis of regulatory $\mathrm{T}$ cell subsets in the peripheral blood of immunoglobulin A nephropathy (IgAN) patients. Genet Mol Res 14: 14088-14092, 2015.

82. Trifari S, Kaplan CD, Tran EH, Crellin NK and Spits H: Identification of a human helper $\mathrm{T}$ cell population that has abundant production of interleukin 22 and is distinct from $\mathrm{T}(\mathrm{H})-17$, $\mathrm{T}(\mathrm{H}) 1$ and $\mathrm{T}(\mathrm{H}) 2$ cells. Nat Immunol 10: 864-871, 2009.

83. Azizi G, Rastegar Pouyani M, Navabi SS, Yazdani R, Kiaee F and Mirshafiey A: The newly identified T helper 22 cells lodge in leukemia. Int J Hematol Oncol Stem Cell Res 9: 143-154, 2015.

84. Xiao C, Xiao P, Li X, Huang G, Li H and Chen Y: Streptococcus may aggravate inflammatory damage in chronic nephritis via the chemotaxis of Th22 cells. Am J Transl Res 11: 7432-7440, 2019.

85. Xiao C, Zhou Q, Li X, Li H, Zhong Y, Meng T, Zhu M, Sun H, Liu S, Tang R, et al: Losartan and dexamethasone may inhibit chemotaxis to reduce the infiltration of Th22 cells in IgA nephropathy. Int Immunopharmacol 42: 203-208, 2017.

86. Liu K, Yang Y, Chen Y,Li S, Gong Y and Liang Y: The therapeutic effect of dendritic cells expressing indoleamine 2,3-dioxygenase (IDO) on an IgA nephropathy mouse model. Int Urol Nephrol 52: 399-407, 2020.

87. Tomino Y, Ozaki T, Koide H, Yagame M, Eguchi K, Nomoto Y and Sakai H: Glomerular T cell and monocyte populations in patients with IgA nephropathy. Nihon Jinzo Gakkai Shi 31: 221-226, 1989.

88. Sabadini E, Castiglione A, Colasanti G, Ferrario F, Civardi R, Fellin G and D'Amico G: Characterization of interstitial infiltrating cells in Berger's disease. Am J Kidney Dis 12: 307-315, 1988.

89. Shimamine R, Shibata R, Ozono Y, Harada T, Taguchi T, Hara K and Kono S: Anti-CD8 monoclonal antibody protects against spontaneous IgA nephropathy in ddY mice. Nephron 78: 310-318, 1998.

90. Johnson RJ, Iida H, Alpers CE, Majesky MW, Schwartz SM, Pritzi P, Gordon K and Gown AM: Expression of smooth muscle cell phenotype by rat mesangial cells in immune complex nephritis. Alpha-smooth muscle actin is a marker of mesangial cell proliferation. J Clin Invest 87: 847-858, 1991.

91. Alpers CE, Hudkins KL, Gown AM and Johnson RJ: Enhanced expression of 'muscle-specific' actin in glomerulonephritis. Kidney Int 41: 1134-1142, 1992.
92. Watanabe T, Kawachi H, Ikezumi Y, Yanagihara T, Oda Y and Shimizu F: Glomerular CD8+ cells predict progression of childhood IgA nephropathy. Pediatr Nephrol 16: 561-567, 2001.

93. Segerer S, Hughes E, Hudkins KL, Mack M, Goodpaster T and Alpers CE: Expression of the fractalkine receptor (CX3CR1) in human kidney diseases. Kidney Int 62: 488-495, 2002.

94. Nishimura M, Umehara H, Nakayama T, Yoneda O, Hieshima K, Kakizaki M, Dohmae N, Yoshie O and Imai T: Dual functions of fractalkine/CX3C ligand 1 in trafficking of perforin ${ }^{+} /$granzyme $^{2}$ $\mathrm{B}^{+}$cytotoxic effector lymphocytes that are defined by CX3CR1 expression. J Immunol 168: 6173-6180, 2002.

95. Addison EG, North J, Bakhsh I, Marden C, Haq S, Al-Sarraj S, Malayeri R, Wickremasinghe RG, Davies JK and Lowdell MW: Ligation of CD8alpha on human natural killer cells prevents activation-induced apoptosis and enhances cytolytic activity. Immunology 116: 354-361, 2005.

96. Yamanaka T, Tamauchi H, Suzuki Y, Suzuki H, Horikoshi S, Terashima M, Iwabuchi K, Habu S, Okumura K and Tomino Y: Release from Th1-type immune tolerance in spleen and enhanced production of IL-5 in Peyer's patch by cholera toxin B induce the glomerular deposition of IgA. Immunobiology 221: 577-585, 2016.

97. Hyun YY, Kim IO, Kim MH, Nam DH, Lee MH, Kim JE, Song HK, Cha JJ, Kang YS, Lee JE, et al: Adipose-derived stem cells improve renal function in a mouse model of Ig A nephropathy. Cell Transplant 21: 2425-2439, 2012.

98. Hong SJ, Traktuev DO and March KL: Therapeutic potential of adipose-derived stem cells in vascular growth and tissue repair. Curr Opin Organ Transplant 15: 86-91, 2010.

99. Chen F, Ma YL, Ding $\mathrm{H}$ and Chen BP: Effects of Tripterygium wilfordii glycosides on regulatory $\mathrm{T}$ cells and Th17 in an IgA nephropathy rat model. Genet Mol Res 14: 14900-14907, 2015.

(i) $९$ This work is licensed under a Creative Commons Attribution-NonCommercial-NoDerivatives 4.0 International (CC BY-NC-ND 4.0) License. 